\title{
Ageing of Thin Gold Films
}

\author{
Hartmann Hieber and Karin Pape
}

Philips GmbH Forschungslaboratorium Hamburg, Federal Republic of Germany

Thin gold metallizations are used in microelectronic devices when high reliability is required. Experience has shown that the operating lives of transistors and monolithic integrated circuits with high power dissipation, and of ultra-bighfrequency devices such as microwave integrated bybrid circuits, are longest when gold is used in the manufacture of their interconnections. With gold, the probability of zero-bour failures and of degradation under thermal and electrical load, and in corrosive environments, is very low. The reasons for the bigh reliability of thin gold metallizations are to be found in the chemical stability of the metal, in the fact that it is not very sensitive to diffusion from other metallizations and in the ease with which connections can be made to it by microwelding $(1,2,3)$.

The limits of stability of polycrystalline thin gold films are imposed by their sensitivity to defect reactions. Faraday showed over a century ago, during his experiments on the transmission of light through flash-evaporated thin gold films, that 'the metal appears to run up into globules' (4). This effect is caused by a slight temperature increase of the adherent thin film/substrate system. Recently, many studies have been made of interdiffusion in multilayer metallizations with gold as a component. The aspects of such interdiffusion which affect phenomena discussed in this article include lowtemperature interactions (5), diffusion with phase formation (6) and grain boundary diffusion $(2,7)$.
Interdiffusion and electrotransport (8) are phenomena resulting from the high driving forces (gradients of the chemical potential, and electric field and current, respectively) to which metallizations may be submitted in service. Because they contain lattice defects such as vacancies, dislocations and grain boundaries in much higher concentrations than do metallizations in thermal equilibrium, as-deposited thin metal films are highly susceptible to these phenomena and to their effects which are undesirable from an engineering point of view. However, at temperatures above absolute zero, such imperfect structures tend to transform into more stable ones. They display low-

Table I

Deposition Data for Thin Gold Film Systems Referred to in This Article

\begin{tabular}{|c|c|c|c|c|c|c|c|c|c|}
\hline \multirow[b]{2}{*}{ Type } & \multicolumn{4}{|c|}{ Adhesion layer } & \multicolumn{5}{|c|}{ Gold film } \\
\hline & deposit & $\begin{array}{l}\text { deposition } \\
\text { method }\end{array}$ & $\begin{array}{c}\text { residual gas } \\
\text { pressure, } \\
\mathrm{Pa}\end{array}$ & $\begin{array}{l}\text { growth } \\
\text { rate, } \\
\mathrm{nm} / \mathrm{s}\end{array}$ & $\begin{array}{c}\text { thickness, } \\
\mathrm{nm}\end{array}$ & $\begin{array}{l}\text { deposition } \\
\text { method }\end{array}$ & $\begin{array}{c}\text { residual gas } \\
\text { pressure, } \\
\mathrm{Pa}\end{array}$ & $\begin{array}{c}\text { tempera- } \\
\text { ture, } \\
\mathrm{K}\end{array}$ & $\begin{array}{l}\text { growth } \\
\text { rate, } \\
\mathrm{nm} / \mathrm{s}\end{array}$ \\
\hline 1 & $\begin{array}{c}10 \mathrm{~nm} \mathrm{NiCr} \\
50 \mathrm{~nm} \mathrm{NiCr} \\
10 \mathrm{~nm} \mathrm{Mo} \\
50 \mathrm{~nm} \mathrm{Mo} \\
50 \mathrm{~nm} \mathrm{Ti}\end{array}$ & evaporated & $<10^{-3}$ & 0.2 & $\begin{array}{c}10^{2} \\
5 \times 10^{2} \\
10^{2} \\
5 \times 10^{2} \\
5 \times 10^{2}\end{array}$ & evaporated & $<10^{-3}$ & 330 & $\sim 0.6$ \\
\hline II & $\begin{array}{l}10 \mathrm{~nm} \mathrm{NiCr} \\
20 \mathrm{~nm} \mathrm{Mo}\end{array}$ & sputtered & $\begin{array}{l}1.2(\mathrm{Ar}) \\
0.7(\mathrm{Ar})\end{array}$ & $\begin{array}{l}0.5 \\
0.5\end{array}$ & $\begin{array}{l}6 \times 10^{2} \\
6 \times 10^{2}\end{array}$ & sputtered & $1.0(\mathrm{Ar})$ & 350 & $\sim 1.0$ \\
\hline III & $1=5-2-x=$ & & & & 370 to 1100 & evaporated & $<5 \times 10^{-7}$ & 296 & 1.2 to 1.8 \\
\hline IV & $10 \mathrm{~nm}$ Mo & sputtered & 0.7 (Ar) & 0.5 & 100 & sputtered & $0.6(\mathrm{Ar})$ & 330 & 0.8 \\
\hline V & $10 \mathrm{~nm}$ Mo & sputtered & 0.7 (Ar) & 0.5 & 50 & sputtered & 0.6 & 330 & 0.8 \\
\hline VI & $50 \mathrm{~nm} \mathrm{Tl}$ & sputtered & $1.3(\mathrm{Ar})$ & 0.6 & 500 & sputtered & $0.8(\mathrm{Ar})$ & 330 & 1.4 \\
\hline VII & $10 \mathrm{~nm} \mathrm{Ti}$ & sputtered & $1.3(\mathrm{Ar})$ & 0.5 & 500 & sputtered & $0.8(\mathrm{Ar})$ & 330 & 0.8 \\
\hline
\end{tabular}


rate ageing effects which are very sensitive to temperature, time and, of course, to features of the initial as-deposited structure. Increasing knowledge of these effects has shown that they may, in fact, be exploited to the advantage of the designer of electronic devices.

The purpose of this article is to review previous work and to discuss results obtained from recent research carried out by the authors on:

(1) How different defect reactions dominate at the various stages of ageing of thin gold films

(2) The effect of ageing on important physical properties of gold metallizations

(3) Which aged metallization structures are desirable for optimum long-term stability of thin gold films.

\section{Sample Preparation}

The substrates for the deposition of thin gold films were $p$-doped silicon single crystals of $\langle 111\rangle$ orientation. They had the same thickness, $0.24 \mathrm{~mm}$, as that used in semiconductor applications. The silicon single crystals had been polished and then oxidized in a water vapourcontaining atmosphere to form a silicon oxide layer $600 \mathrm{~nm}$ thick and of composition between $\mathrm{SiO}_{1.5}$ and $\mathrm{SiO}_{1.8}$. The oxide was amorphous and showed no surface irregularities visible by light interference microscopy or in transmission electron microscopy (TEM) of replicas. These techniques would have revealed a surface roughness greater than the thickness of the following adhesion layer.

Adhesion layers were deposited on the samples for recovery experiments. The thickness of these layers was such that the heat treatments did not cause loss of adhesion of the thin gold films under investigation $(9,10)$. The gold films for the recrystallization experiments were evaporated without adhesion layers in order to avoid, at a later stage, anchoring of grain boundaries in them by species which diffused from the adhesion layer (11). Table I shows the deposition conditions for the metallizations discussed in this article.

The purity of the sputter targets and of the ingots for electron beam evaporation was better than 99.998 weight per cent. The residual gas pressures and the growth rates reported in Table I were selected to ensure that the gold deposits had a concentration of impurities of less than $20 \mathrm{ppm}$. The sputtered layers contained a small amount of sputter gas (argon) trapped in grain boundaries and pores in the metallization. The films used for the recrystallization experiments were evaporated in ultra-high vacuum and had an impurity level of less than $10 \mathrm{ppm}$.

Figure 1 shows schematically the cross-section of the samples. After chemical dissolution of the adhesion layers and thinning by ion etching, the gold had a grain size of about 100 to $150 \mathrm{~nm}$ (Figure 2). Ion-etching of both sides of

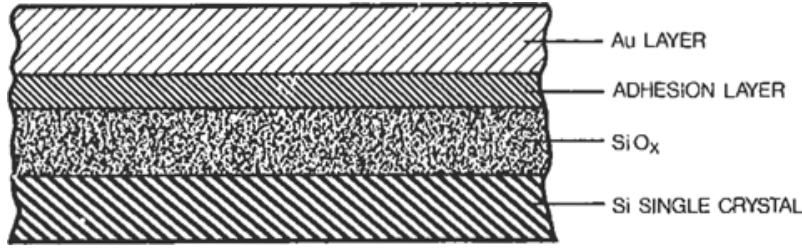

Fig. 1 Schematic cross-section of the metallizations used for this study

the thin gold films revealed that the grain sizes on both their bottom and top surfaces were similar.

Mechanical wiping and scratching affect the behaviour of freshly deposited metallizations during subsequent heat treatment (9). Therefore, only thin films with undamaged surfaces were used for the ageing experiments.

\section{Recovery}

Fine-grained thin films contain higher concentrations of lattice defects than does metal in bulk form. They are in a thermodynamically unstable state and, upon increasing their temperature to just below the melting point of the metal, their free energy can be lowered by the annihilation and rearrangement of lattice defects in various ways.

Fig. 2 Transmission electron micrograph of an evaporated thin gold film removed from the silicon substrate by chemical dissolution of the adhesion layer and thinned by ion etching from the side of the adhesion layer

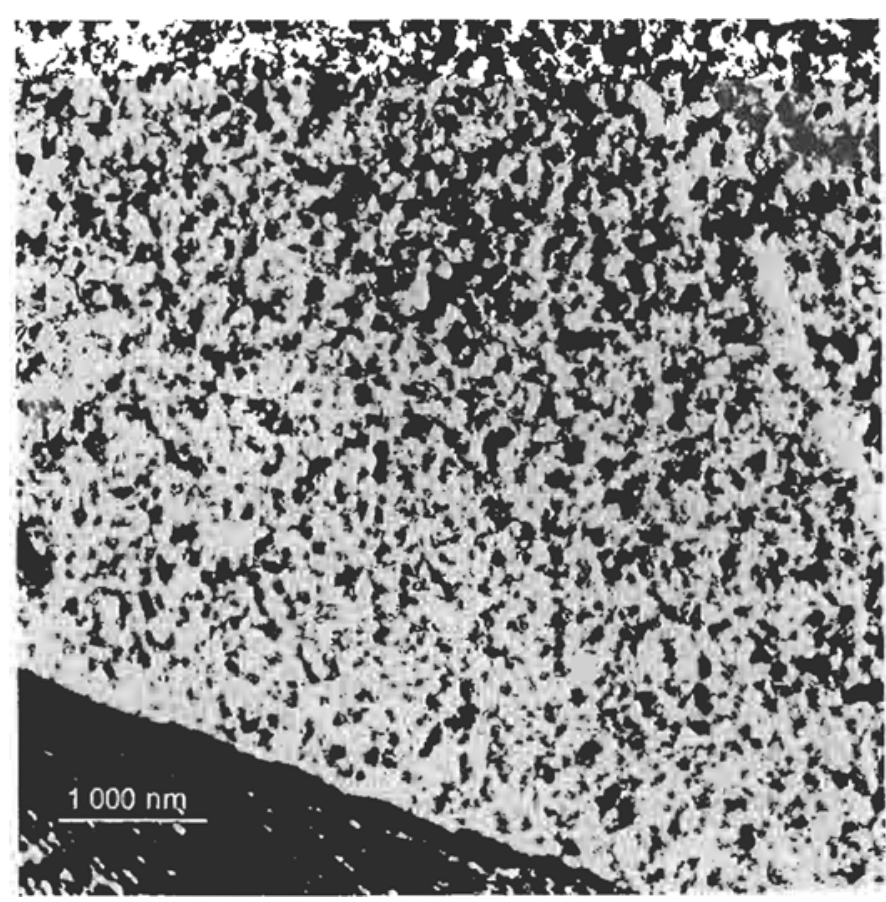




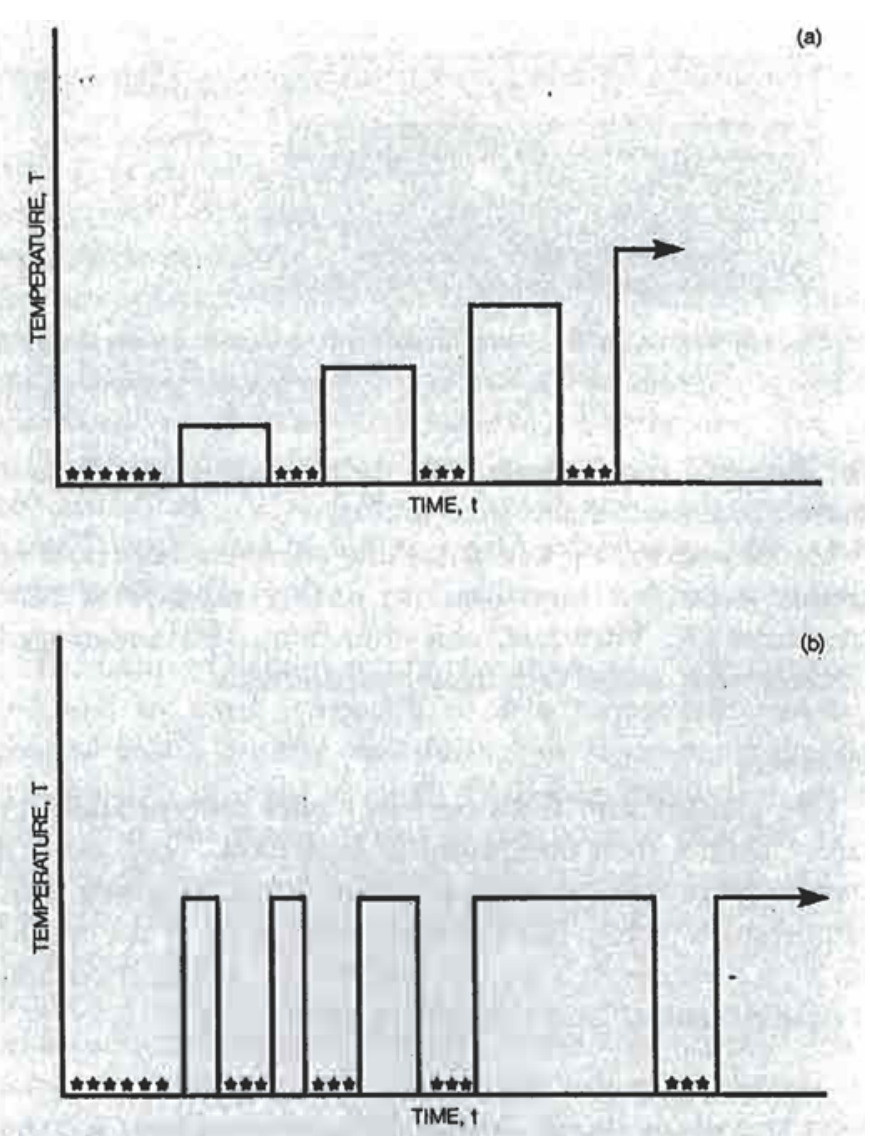

Fig. 3 Temperature, $T$, against time, $t$, relationship for samples submitted to (a) isochronal and (b) isothermal heat treatments. The resistance measurements were all made at a teference temperature (78 or $309.2 \mathrm{~K}$ ) at times marked by an asterisk

The fundamental structural processes which may be involved during annealing of materials containing defects fall into five categories. These are (12):

(i) Reactions of point defects and of clusters of them; in particular the annihilation of interstitials and vacancies

(ii) The annihilation of dislocations of opposite sign and the shrinking of dislocation loops

(iii) The rearrangement of dislocations from high energy configurations to lower energy configurations

(iv) The absorption of point defects and dislocations by grain boundaries migrating through the metal

(v) The reduction of the total grain boundary area.

Generally, a polycrystalline metal does not attain thermodynamic stability by a single process. In fact, all the reactions mentioned above contribute to the process either singly or simultaneously.

The defect structures in condensed thin films are comparable to those in polycrystalline bulk metals quenched from high temperatures, or to those in irradiated materials. Processes (i) and (ii) are observed upon annealing of such structures. When considered together, processes (i) and (ii) are termed recovery. Processes (iv) and (v), which involve migration of large-angle grain boundaries, are termed recrystallization. The intermediate process (iii) contributes to the formation of small-, as well as large-angle grain boundaries, and is regarded as a part of recrystallization.

A useful tool for investigating defect reactions is the measurement of DC electrical resistance. The reasons for this are the ease of achieving high accuracies and the possibility of comparing readily the behaviour of different samples. An essential condition is that the DC resistance should continually increase with the duration of the ageing treatment. Another is that the resolution of the measuring equipment should be high compared to the changes in resistance during ageing.

In the measurement of DC resistances for this investigation, 16 different values of DC current were used. When fitting the slope of the measured voltages, an accuracy of $1.65 \times 10^{-5}$ was reached for resistance values from $0.1 \mathrm{ohm}$ upwards. The resistances of the samples were compared to that of a standard measured simultaneously. The resulting plots show the deviations of the resistance of each sample, after each heat treatment step, from its initial resistance before ageing.

Figure 3 schematically shows the sequence of measurements and of heat treatments. Both isochronal and isothermal treatments are used to determine the thermal activation energy $Q$ of the ageing process (13). If only one of the ageing mechanisms, numbered (i) to (v) above, is active, the change in the average concentration $C$ of the reacting defects is given by:

$$
\Delta C=-\alpha C^{\gamma} \exp (-Q / T)
$$

where:

$\alpha$ is the reaction rate

$\gamma$ is the reaction order

$k$ is the Boltzmann constant

$Q$ is a sensitive indicator of the kind of atomistic reaction occurring and is the physically interesting parameter in this relationship.

Figure 4 shows the changes in the DC resistances during isochronal heat treatments of different evaporated gold/adhesion layer combinations. In the system gold/nickel-chromium, alloying of the gold by diffusion of the nickel and chromium occurs. The relative changes in the DC resistance during ageing are higher for the thinner film combinations at lower temperatures. In the system gold/molybdenum, recovery occurs independently of the 
layer thickness. This was confirmed by tests on gold/molybdenum metallizations prepared under various conditions of residual gas pressure, growth rate and heat source - electron beam gun or resistance heating.

The temperature against time correlations shown in Figure 5 are obtained from the values of these two parameters yielding equal changes in resistance during isochronal and isothermal heat treatments. The gold/molybdenum combination, in which no interdiffusion occurs, yields a thermal activation energy for ageing between that for the migration of vacancies in gold, $0.93 \mathrm{eV}(14)$, and that for selfdiffusion in gold, $1.7 \mathrm{eV}$ (15). The recovery of the gold/nickel-chromium system has a thermal activation energy near that for grain boundary interdiffusion, about $0.5 \mathrm{eV}(2)$.

The holding time during the isochronal heat treatments ( 1 hour) covers the initial stage of recovery. This is also true for the gold/nickel-chromium system in which diffusion takes place. Figure 6 shows the changes in resistance of various thin film combinations, measured with an accuracy of $1.6 \times 10^{-5}$. The resolution of the recovery effect is improved by using heat treatments of short duration.

Recovery is defined as continuing until a resistance minimum occurs, and up to this point no change was observed in the grain size of gold films and, using TEM, no marked grain growth was found. Upon completion of recovery, the resistance increases, due to the diffusion of nickel and chromium into the gold. Figure 7 shows concentration against depth profiles measured by secondary ion mass spectrometry before and after isochronal ageing of a gold/nickel-chromium sample. The high surface concentrations of chromium and nickel are caused by grain boundary diffusion, and surface sinking results from the oxidation of these metals at the free surface of the gold.

Thin gold films with titanium adhesion layers show an identical recovery process followed by interdiffusion. However, here the first steps of phase formation have been observed (16). The formation of the $\mathrm{Au}_{4} \mathrm{Ti}$ phase - after 10 minutes at $573 \mathrm{~K}$ - was rather faster than indicated by other experiments (6).

\section{Recrystallization}

The behaviour of high-angle grain boundaries is sensitive to the presence of impurities, so our recrystallization study was made on gold films evaporated directly onto oxidized silicon in ultra-high vacuum (Type III of Table I).

The time and temperature ranges for the heat treatments were from 1 to $384 \mathrm{~h}$ and 370 to $570 \mathrm{~K}$, respectively. The lower limits were set to ensure that the recovery process was completed, while the upper limits coincided with the start of crystallization effects on the surface of the gold (see below).

Gold-coated substrates without adhesion layers were

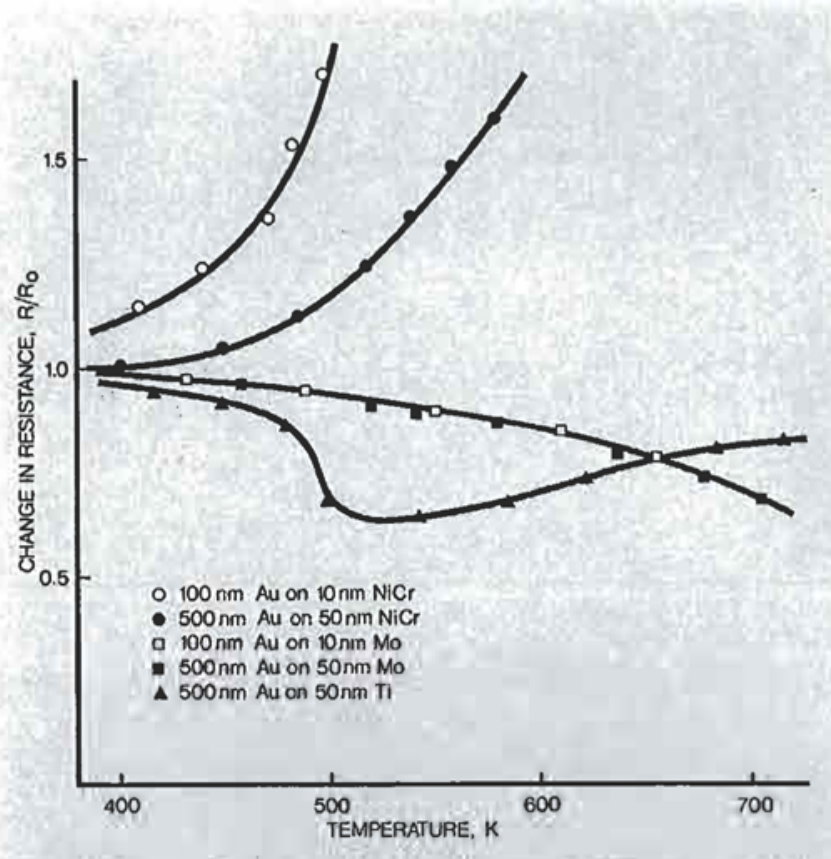

Fig. 4 Changes in resistance during $1 \mathrm{~h}$ anneals of evaporated gold films on various adhesion layers (Type I, Table I)

Fig. 5 Temperature-time correlations for the ageing of thin gold film combinations - from data giving equal changes in resistance during both types of heat treatment

$A=500 \mathrm{~nm}$ gold on $50 \mathrm{~nm}$ molybdenum, $Q=1.5 \pm 0.04 \mathrm{eV}$

$\mathrm{B}=500 \mathrm{~nm}$ gold on $50 \mathrm{~nm}$ nickel-chromium, $Q=0.68 \pm 0.03 \mathrm{eV}$ $C=100 \mathrm{~nm}$ gold on $10 \mathrm{~nm}$ molybdenum, here two different kinetics ate visible, $Q \approx 0.97 \mathrm{eV}$ and $Q>1.8 \mathrm{eV}$

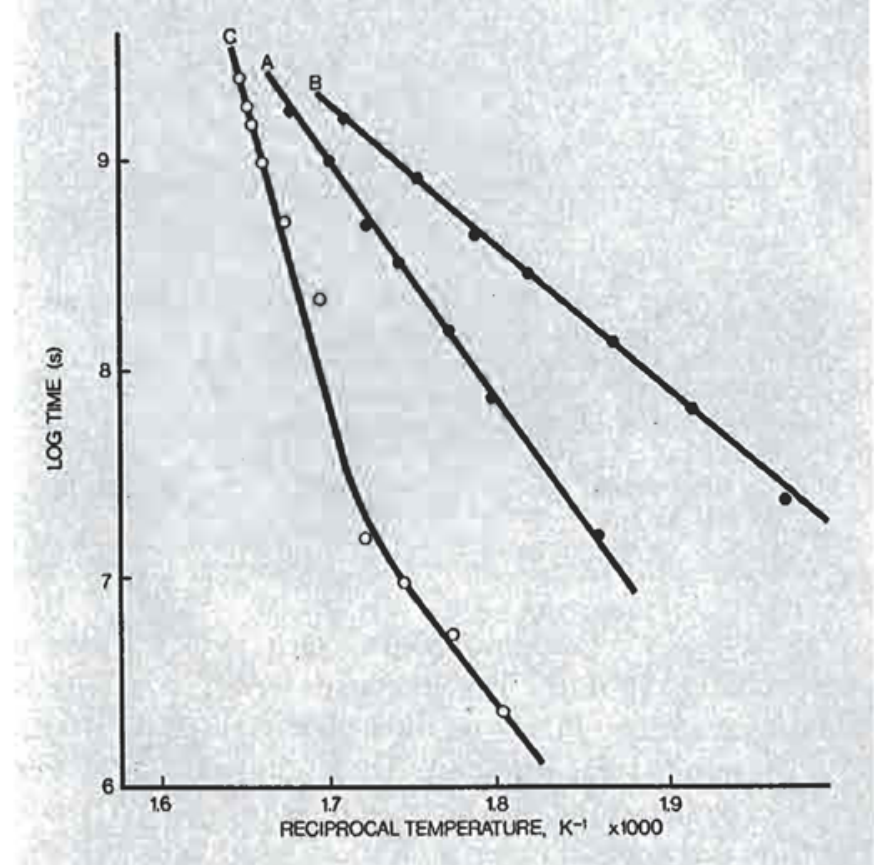



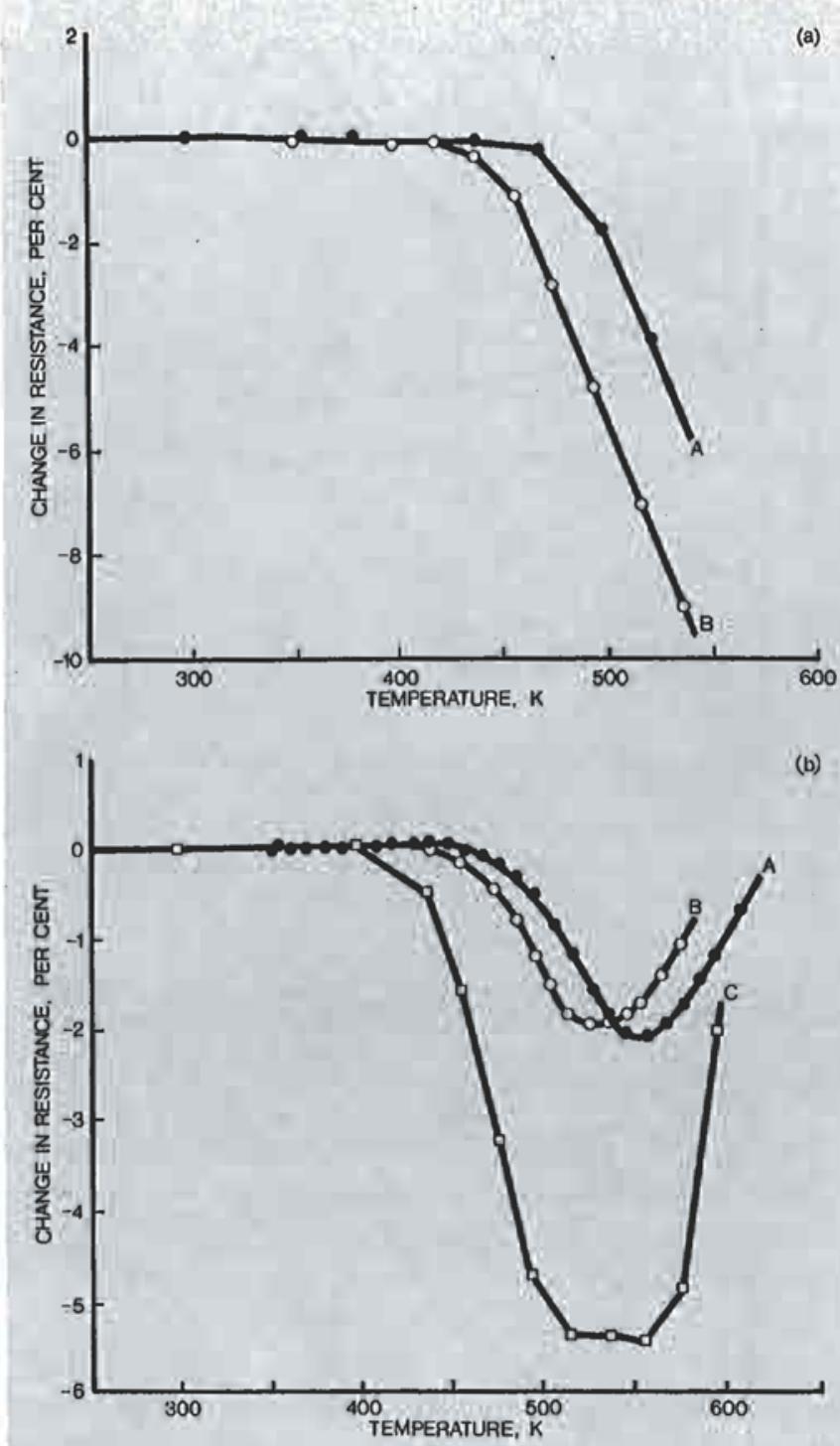

Fig. 6 Changes in resistance during isochronal heat treatments (measuring temperature $309.2 \pm 0.01 \mathrm{~K}$ )

(a) Type II metallization $(\mathrm{A}=$ with $20 \mathrm{~nm}$ molybdenum, $\mathrm{B}=$ with $10 \mathrm{~nm}$ nickel-chromium adhesion layer) of Table I

(b) Type I metallization ( $500 \mathrm{~nm}$ gold on $50 \mathrm{~nm}$ nickel-chromium) of Table I
A $t=2 \mathrm{~min}$
B $t=10 \mathrm{~min}$
C $\mathrm{t}=45 \mathrm{~min}$

scratched and broken into pieces, each with an area of approximately $25 \mathrm{~mm}^{2}$. The specimens were then subjected to heat treatment in air or ultra-high vacuum (less than $10^{-8} \mathrm{~Pa}$ residual gas pressure). The samples for TEM were prepared by detaching the thin gold films from the substrate. The films did not curl up on separation, which indicated that

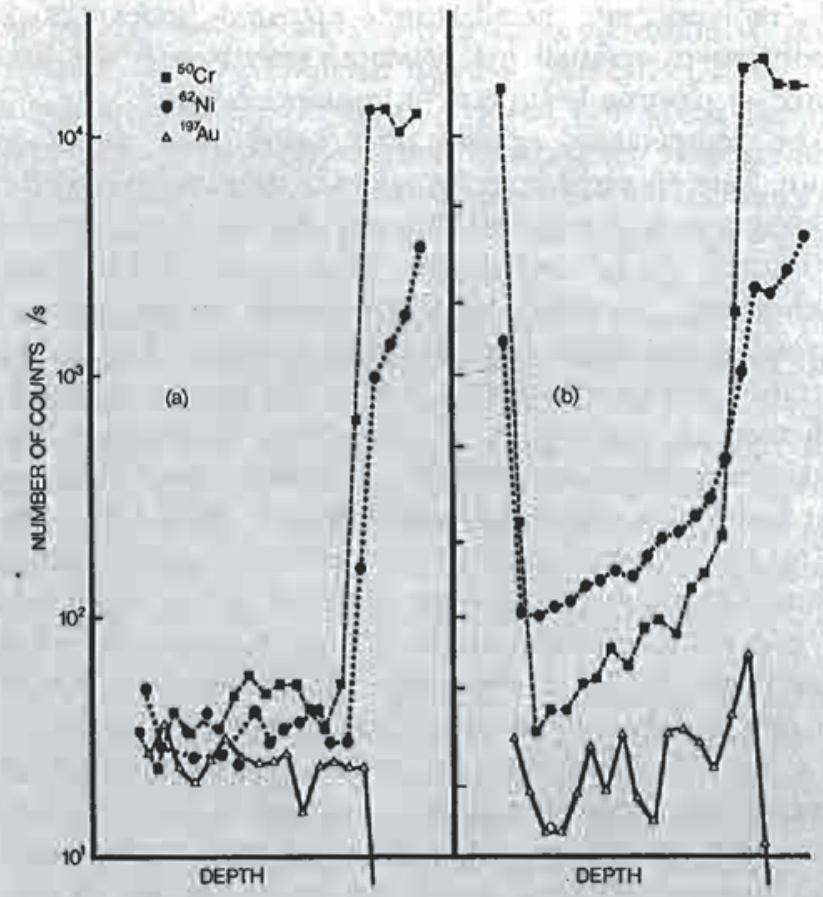

Fig. 7. Depth profiles of the $500 \mathrm{~nm}$ gold $/ 50 \mathrm{~nm}$ nickel-chromium thin film combination, obtained by secondary ion mass spectrometry (a) depth profile of an as-deposited sample

(b) depth profile of a sample aged for 45 minutes (see curve $C$ in Figure 5)

they were stress-free. After fixing portions of the films to a grid support, thinning was carried out by ion etching with the accompanying temperature increase being limited to $5 \mathrm{~K}$.

The films were studied in a microscope in beams of 80 and $100 \mathrm{kV}$ electrons. Bright-field images were used for the determination of the average grain diameters (calculated from the number of large-angle grain boundaries intercepted by cross-lines). Dark-field images were used to establish the orientation of individual grains. The indexing of the diffraction patterns was carried out using the ratio method (17).

\section{Grain Orientation}

Comparison of TEM micrographs of gold films which had been thinned from either the free surface or from the interface with the substrate, with micrographs of as-deposited films which were sufficiently thin for direct observation in the microscope, showed no marked differences in the grain structures. This indicates that continuous nucleation and columnar grain growth occur during deposition. In several areas of the gold layers, the orientations of the as-deposited grains were not distributed statistically; there were local 


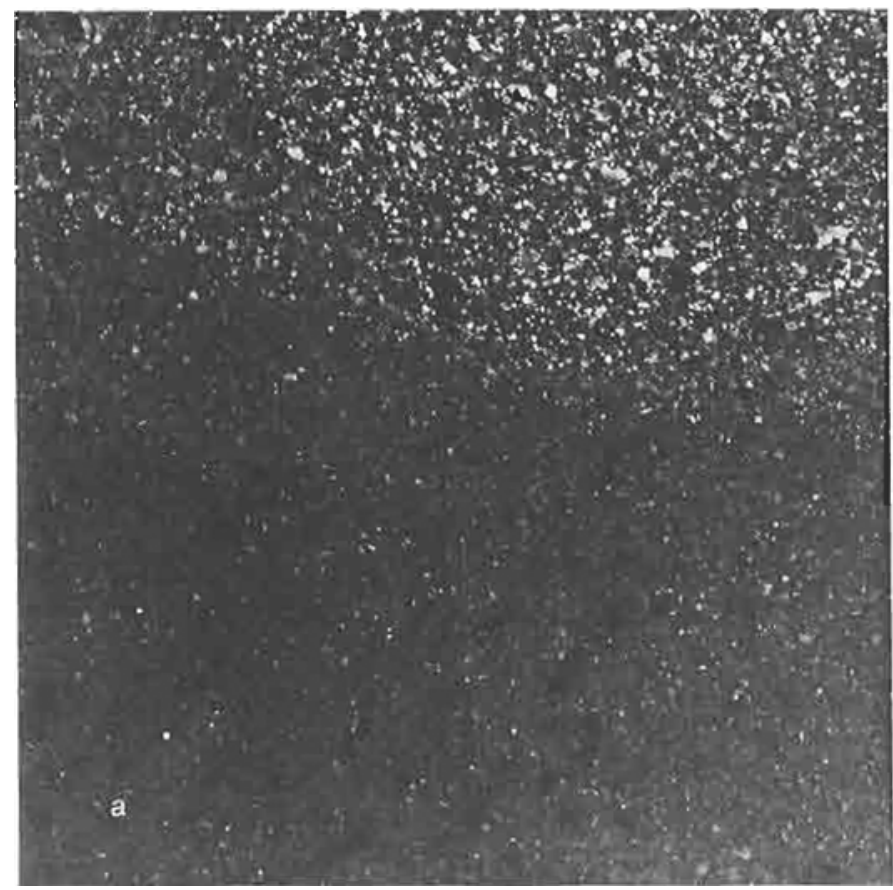

Fig. 8 Dark-field transmission electron micrographs of a $90 \mathrm{~nm}$ thick gold film deposited in ultra-high vacuum (Type III of Table I)

(a) Beam tilt for illumination with a $\{200\}$ reflexion; $<100>$ grains are bright

accumulations of certain crystal types. For example, a concentration of $<100\rangle$ grains can be seen in the upper part of Figure $8(a)$, while $\langle 110\rangle$ grains predominate in the middle part of Figure 8 (b). Results such as these indicate that many TEM observations are necessary if reliable conclusions are to be drawn on the recrystallization structures of, and grain growth in, thin films. From numerous observations it has been estimated that more than 80 per cent of the recrystallized gold film areas had even distributions of $\langle 100\rangle,\langle 110\rangle,\langle 111\rangle,\langle 311\rangle,\langle 331\rangle$ and $<210>$ grains.

\section{Grain Size}

The average grain size $\bar{D}_{0}$ measured on the free surface of as-deposited gold films somewhat increases with the film thickness $d$. For instance, when $d$ increases from 90 to $370 \mathrm{~nm}, \bar{D}_{0}$ increases slightly from 50 to $60 \mathrm{~nm}$, and when $d$ reaches $670 \mathrm{~nm}, \bar{D}_{0}$ rises to $250 \mathrm{~nm}$.

During heat treatment in air or in vacuum, the thin films show marked, but uneven, grain growth. Figure 9 shows the structure of a $370 \mathrm{~nm}$ thick gold film before and after heat treatment in ultra-high vacuum. The large grains present after annealing have a $<100\rangle$ orientation (11).

In order to produce elongated grains of up to $1500 \mathrm{~nm}$, thicker gold films ( 670 or $1100 \mathrm{~nm}$ ) had to be heat-treated,

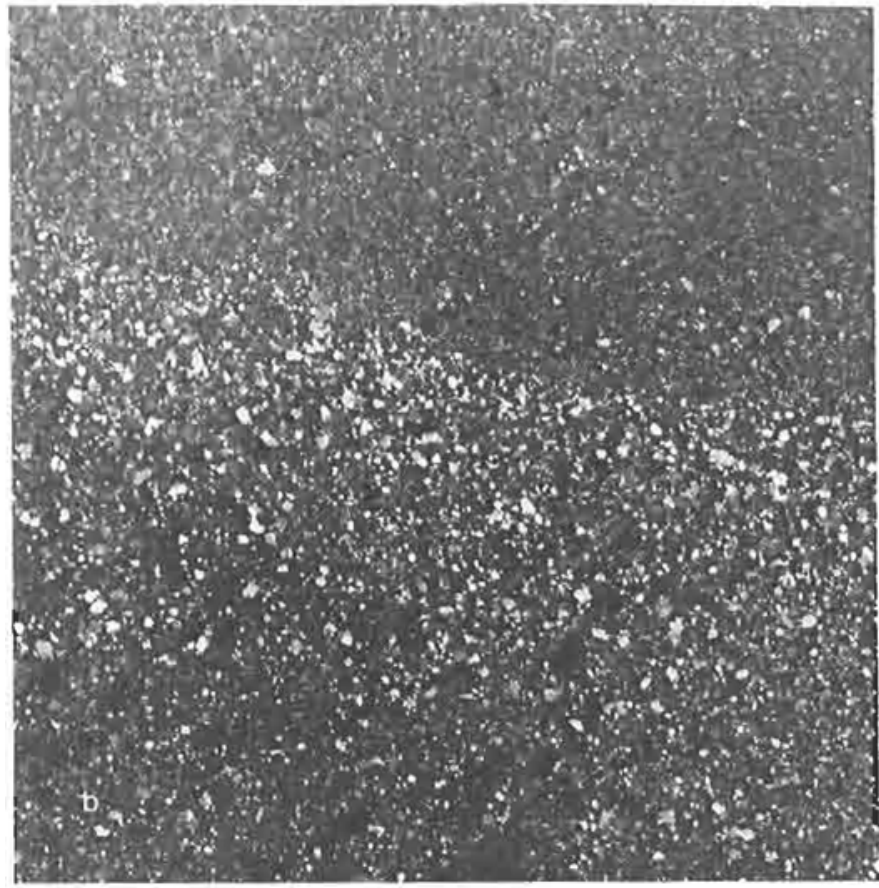

(b) Beam tilt for illumination with a $\{220\}$ reflexion; $<110\rangle$ grains are bright

Both micrographs show the same section of the film at a magnification of $\times 4000$

Fig. 9 Bright-field micrographs of a $370 \mathrm{~nm}$ thick gold film before (inset) and after a heat treatment in ultra-high vacuum at $480 \mathrm{~K}$ for $40 \mathrm{~h} \times 42000$

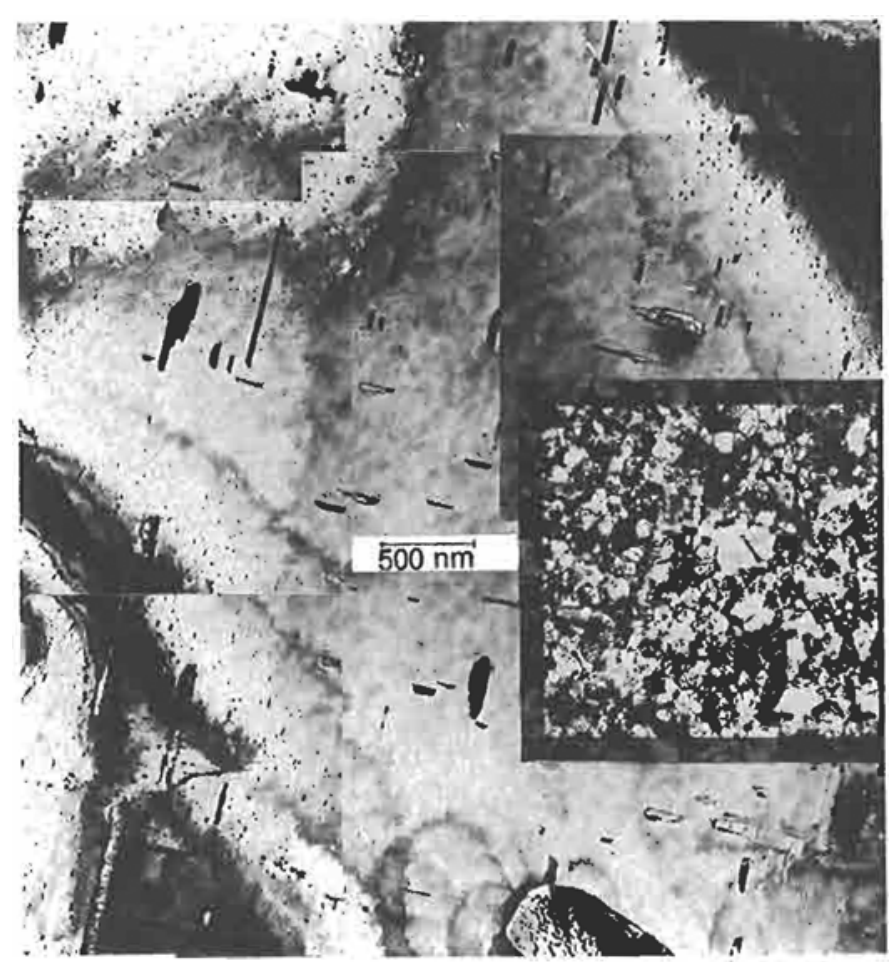




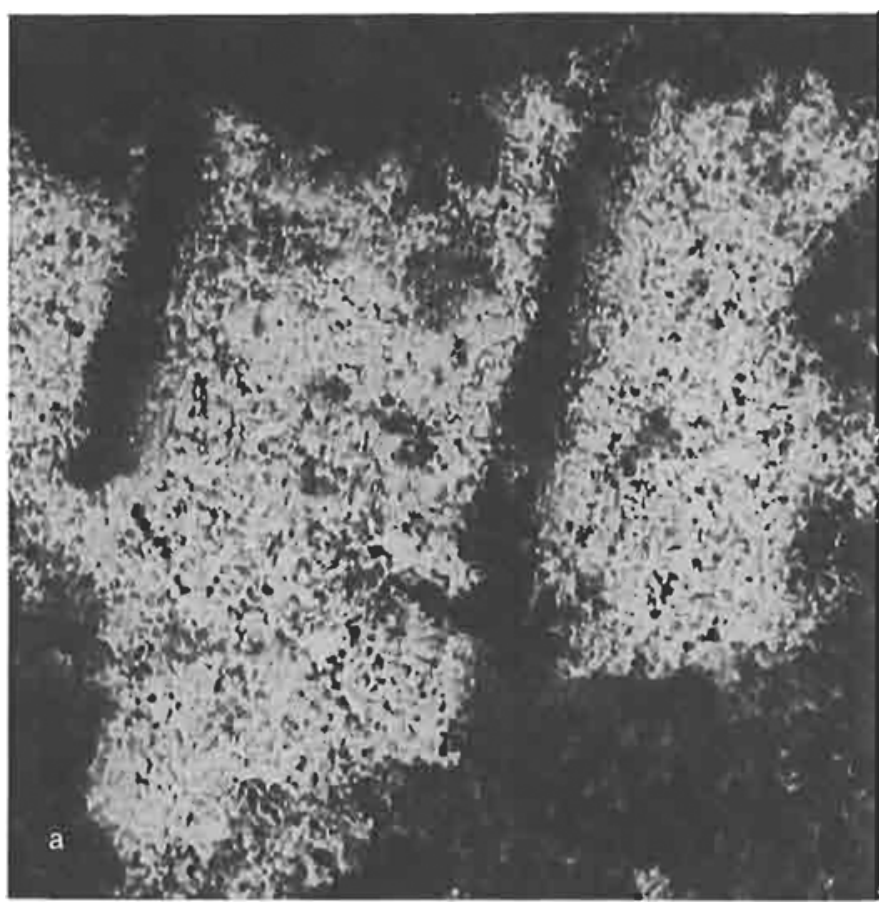

Fig. 10 (a) Bright-field micrograph of a $<100>$ grain with twins

(b) Selected-area diffraction pattern of (a)

(c) SEM secondary electron image of a larger $<100>$ grain also with twins

$\times 10000$

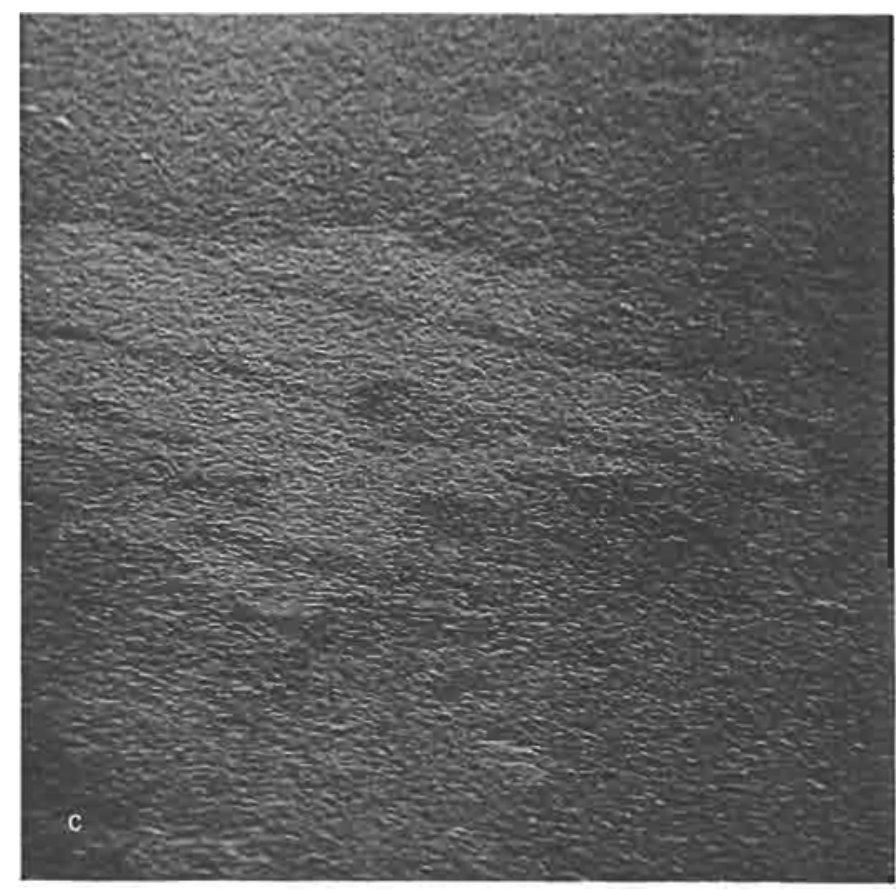

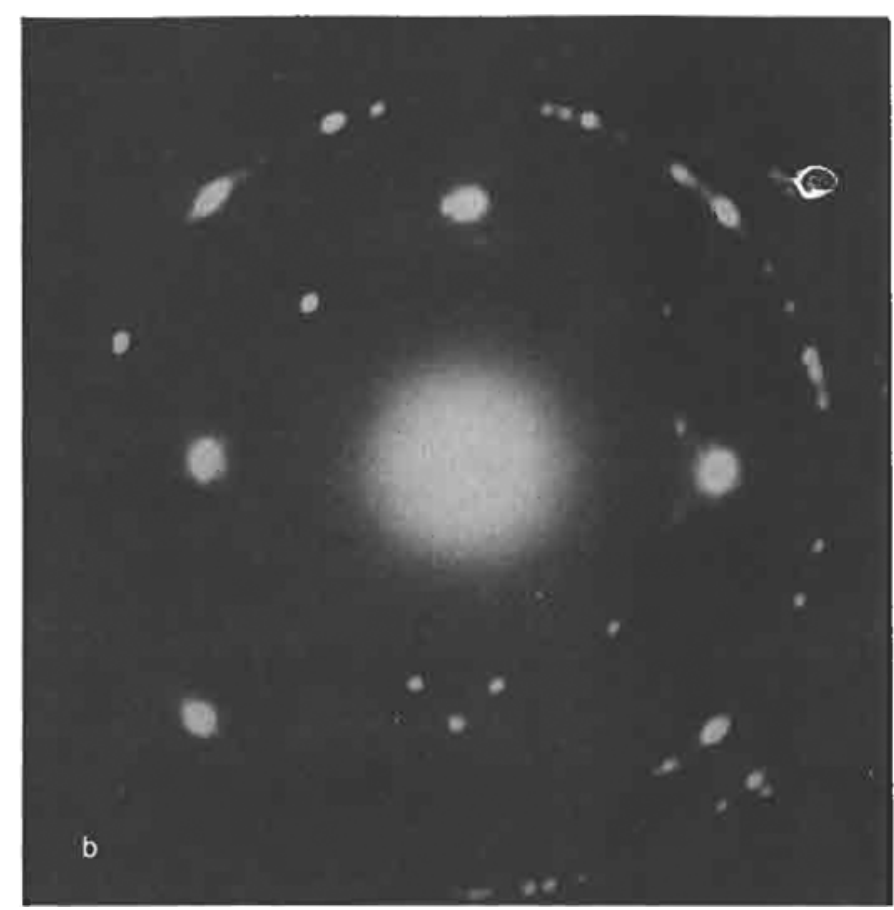

but only for a short time ( 1 to $5 \mathrm{~h}$ at 480 to $580 \mathrm{~K}$ ). Grain growth in the $1100 \mathrm{~nm}$ thick films was always inhomogeneous, large elongated grains being found adjacent to finegrained areas.

From the observation of numerous TEM micrographs, the conclusion can be drawn that a well-defined and simple distribution of grain sizes in the as-deposited condition results in the growth of uniformly sized grains during recrystallization and conversely (11). Table II illustrates this conclusion with some typical results.

Scanning electron microscope (SEM) observations confirm the phenomena detected in the TEM micrographs. The bright-field TEM micrograph of Figure 10 (a) shows twins in a $<100>$ grain as small, contrasted rectangles. The coherent twin boundaries are long and straight, whereas the incoherent boundaries are short and jagged. The twin planes have $\{111$ indices and the corresponding diffractions are found in all the patterns obtained from discontinuously grown $<100\rangle$ grains (Figure $10(\mathrm{~b})$ ).

In the SEM secondary electron image, the different grain orientations lead to different image intensities. The elongated grains and the twins are clearly distinguishable (Figure $10(\mathrm{c})$ ).

\section{Driving Forces and Growth Limits}

The recrystallization of bulk metals by nucleation of new grains and their growth requires nuclei with a minimum size of about $1000 \mathrm{~nm}$. These have low defect densities and may 
form as a result of grain boundary migration into grains with high defect densities (18). The thin gold films discussed here had initial grain sizes which were much smaller (Table II).

Nucleation of new grains is not required for recrystallization which may also occur by grain growth alone. This is indeed what we observed in thin gold films. However, the mechanism of grain growth has not yet been modelled quantitatively (19) and only qualitative experimental data are available concerning the dependence of grain boundary mobility on the driving forces produced by different kinds of lattice defects.

The forces driving or retarding grain boundary movement in thin gold films are listed in Table III. The annihilation of dislocations and the reduction of the grain boundary area per unit volume are the most effective driving forces. The maximum recrystallization grain size $\bar{D}_{\text {lim }}$ is determined by the equilibrium between these two driving forces and the retarding force due to surface grooving (Table III) yielding:

$$
\bar{D}_{\lim }=12 d
$$

Table IV shows the maximum grain sizes observed by us to be comparable with this estimated value.

\section{Crystal Ripening}

Heat treatment of thin gold films at elevated temperatures and for several days leads to the formation of gold crystallites on their surfaces. Figure 11 shows how this phenomenon characteristically begins with local thickening and pore formation in a gold/molybdenum metallization. The material which is necessary for the local thickening migrates

\begin{tabular}{|c|c|c|c|c|c|}
\hline \multirow{3}{*}{$\begin{array}{c}\begin{array}{c}\text { Film } \\
\text { thickness, } \\
\text { nm }\end{array} \\
90\end{array}$} & \multicolumn{4}{|c|}{$\begin{array}{l}\text { Table II } \\
\text { yypical Grain Sizes of Thin Gold Films } \\
\text { ipe III of Table I) after Heat Treatments }\end{array}$} & \multirow[b]{2}{*}{$\max$} \\
\hline & $\begin{array}{c}\text { Heat } \\
\text { treatment } \\
\text { temperature, } \\
\text { K }\end{array}$ & $\begin{array}{l}\text { Heat } \\
\text { treatment } \\
\text { time, } \\
\text { h }\end{array}$ & \multicolumn{2}{|c|}{ Grain size, nm } & \\
\hline & - & - & 60 & 25 & 250 \\
\hline & $\begin{array}{l}480 \\
570\end{array}$ & $\begin{array}{l}1 \\
1\end{array}$ & $\begin{array}{l}130 \\
170\end{array}$ & $\begin{array}{l}50 \\
50\end{array}$ & $\begin{array}{l}800 \\
800\end{array}$ \\
\hline & $\begin{array}{l}370 \\
470 \\
570\end{array}$ & $\begin{array}{l}5 \\
5 \\
5\end{array}$ & $\begin{array}{r}75 \\
110 \\
110\end{array}$ & $\begin{array}{l}25 \\
25 \\
50\end{array}$ & $\begin{array}{l}250 \\
600 \\
900\end{array}$ \\
\hline I & $\begin{array}{l}370 \\
450 \\
570\end{array}$ & $\begin{array}{l}168 \\
168 \\
384\end{array}$ & $\begin{array}{l}130 \\
130 \\
190\end{array}$ & $\begin{array}{l}50 \\
50 \\
80\end{array}$ & $\begin{array}{r}900 \\
900 \\
1400\end{array}$ \\
\hline 670 & - & - & - & 110 & $\sim 1100$ \\
\hline & $\begin{array}{l}370 \\
480 \\
570\end{array}$ & $\begin{array}{r}- \\
-\end{array}$ & $\begin{array}{l}- \\
- \\
-\end{array}$ & $\begin{array}{l}120 \\
200 \\
790\end{array}$ & $\begin{array}{l}\sim 800 \\
>1500 \\
>1500\end{array}$ \\
\hline & $\begin{array}{l}370 \\
480 \\
570\end{array}$ & $\begin{array}{c}- \\
-\end{array}$ & $\frac{-}{-}$ & $\begin{array}{l}170 \\
\frac{860}{86}\end{array}$ & $\begin{array}{l}\sim 1000 \\
>5000 \\
\sim 5000\end{array}$ \\
\hline & $\begin{array}{l}370 \\
480 \\
570\end{array}$ & $\begin{array}{l}168 \\
180 \\
168\end{array}$ & $\frac{-}{-}$ & $\begin{array}{r}240 \\
1010 \\
1610\end{array}$ & $\begin{array}{l}\sim 25000 \\
\sim 6500 \\
\sim 6500\end{array}$ \\
\hline
\end{tabular}

Table III

Forces Driving or Retarding the Motion of a Grain Boundary

\begin{tabular}{|c|c|c|c|c|}
\hline $\begin{array}{l}\text { Cause of } \\
\text { the force }\end{array}$ & Formula & $\begin{array}{l}\text { Parameter values } \\
\text { for gold thin films }\end{array}$ & $\begin{array}{l}\text { Driving } \\
\text { forces, } \\
\mathrm{N} / \mathrm{m}^{2}\end{array}$ & $\begin{array}{l}\text { Retarding } \\
\text { force, } \\
\mathrm{N} / \mathrm{m}^{2}\end{array}$ \\
\hline $\begin{array}{c}\text { 1. deformation } \\
\text { energy }\end{array}$ & $p \cong \rho G b^{2}$ & $\rho=10^{11}$ to $10^{12} / \mathrm{cm}^{2}$ & $10^{7}$ to $10^{8}$ & \\
\hline 2. GB energy & $\mathrm{p} \cong \frac{3 \gamma_{G B}}{\bar{D}}$ & $D=50$ to $170 \mathrm{~nm}$ & $10^{7}$ to $10^{6}$ & \\
\hline $\begin{array}{l}\text { 3. difference in surface energy } \\
\text { of adjacent grains }\end{array}$ & $p \cong \frac{2 \Delta \gamma_{s}}{d}$ & $\begin{array}{c}\mathrm{d}=90 \text { to } 1100 \mathrm{~nm} \\
\Delta \gamma_{\mathrm{s}} \geqslant 0.1 \mathrm{~J} / \mathrm{m}^{2}\end{array}$ & $10^{8}$ to $10^{5}$ & \\
\hline $\begin{array}{l}\text { 4. thermally induced } \\
\text { mechanical stress }\end{array}$ & $\mu=\frac{1 \tau^{2}}{2 E}$ & $\begin{array}{c}\Delta \alpha=7 \times 10^{-6 / K} \\
\Delta T \cong 200 \mathrm{~K}\end{array}$ & $10^{5}$ to $10^{6}$ & \\
\hline 5. surface grooving & $\mathrm{p} \cong \frac{\gamma^{2} \mathrm{~GB}}{2 \mathrm{~d} \gamma_{\mathrm{s}}}$ & $d=90$ to $1100 \mathrm{~nm}$ & . & $10^{6}$ to $10^{5}$ \\
\hline
\end{tabular}




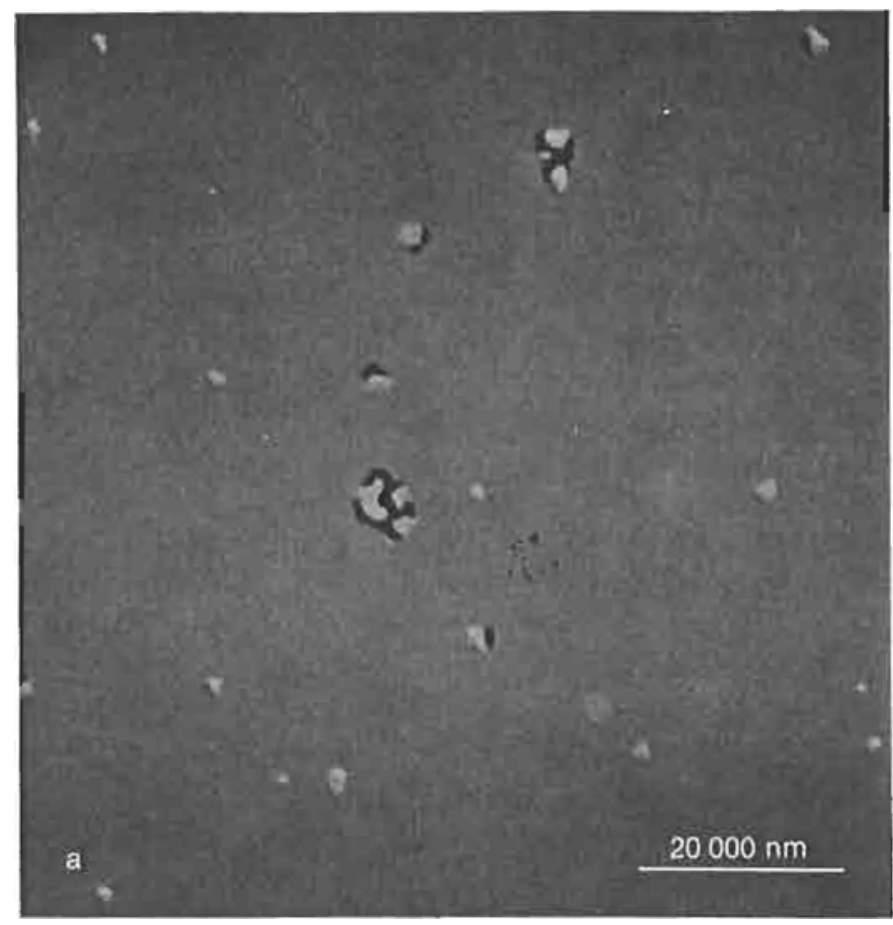

Fig. 11 Local thickening and pore formation during extended heat treatments of gold thin films

(a) Type IV metallization of Table I, heat treated by linearly increasing temperature from 323 to $526 \mathrm{~K}$ over $41 \mathrm{~h}$ in laboratory air $\quad \times 8000$

(b) Type $\mathrm{V}$ metallization, heat treated at $684 \mathrm{~K}$ for $169 \mathrm{~h}$ in helium

$\times 2300$

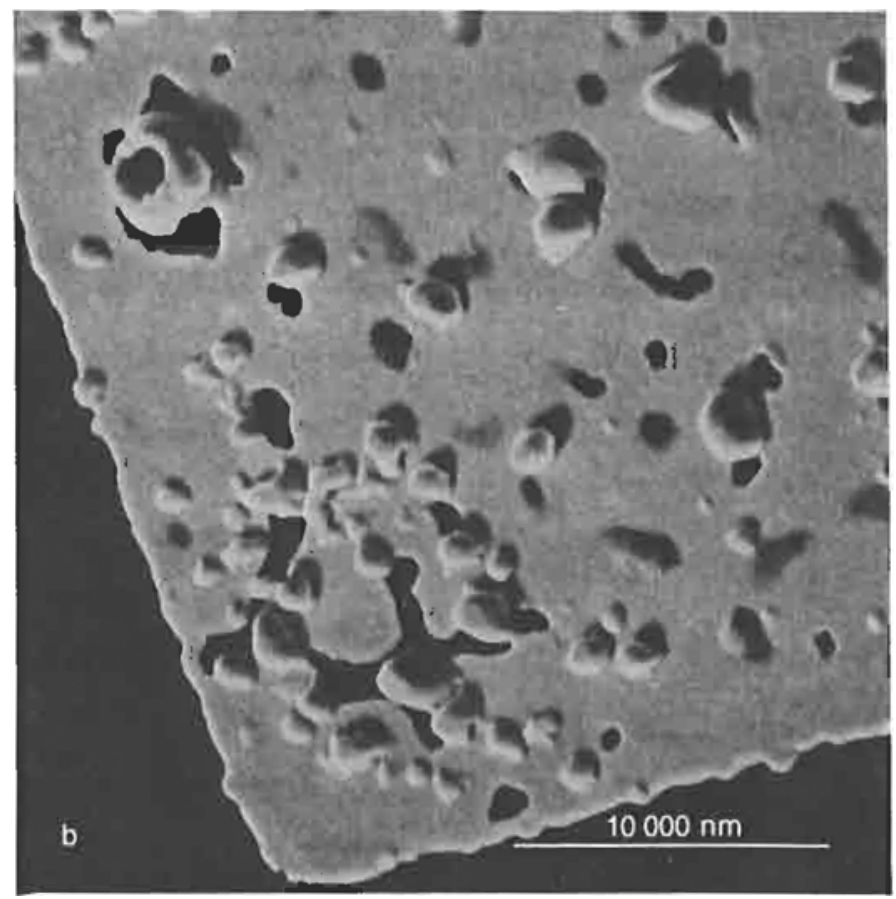

from the thin film sites adjacent to the growing area. The thicker parts are connected to the residual thinned gold film, so that local thickening is different from the classical process of ripening of a separated crystal on a carrier, or in a transport medium.

If the gold film is sufficiently thick, and there is a relatively thin adhesion layer of titanium or molybdenum, faceted single crystals of gold are formed in an inert gas atmosphere (Figure 12). These crystals have the shape of truncated octahedra which is that with minimum surface energy for fcc single crystals (20). The crystals have a $\{111\}$ axis perpendicular to the thin film plane, which has been found to be the preferred orientation of dendrites of gold growing on amorphous substrates (21). The time required for producing ripened crystals with a size of $1000 \mathrm{~nm}$ or more is 65 hours at $523 \mathrm{~K}$ or 20 hours at $673 \mathrm{~K}$. These crystals are chemically pure, containing less than 0.1 weight per cent of the adhesion layer metal (for example, titanium) - the residual gold layer contains the diffused species (22).

The thin gold films are not subjected to a temperature gradient, an electric current or a chemical potential gradient during heat treatment. Possible transport mechanisms are therefore surface diffusion and/or bulk diffusion and/or diffusion along defect paths such as grain boundaries and dislocations. Evaporation and re-condensation can be excluded, because the cold spots in the furnaces used for our experiments would have acted as sinks for any vapour which was present, and on account of the low vapour pressure of gold at the temperatures employed.

At low temperatures, transport phenomena with low thermal activation energies are more effective than those with high thermal activation energies. Thus, surface self-diffusion of gold with an activation energy of $0.23 \mathrm{eV}(23)$ and grain boundary diffusion with an activation energy of about $0.5 \mathrm{eV}$ $(9,24)$ are more effective than other transport phenomena at these temperatures. The relaxation of stresses in the thin gold film could provide the necessary driving force.

Table IV

The Limit of Grain Growth Given by Equating Causes 2 and 5 of Table III

\begin{tabular}{c|c}
\hline$d$, & Observed $D_{\max }$ \\
\hline $\mathrm{nm}$ & \\
\hline 90 & $2 \mathrm{~d}$ to $15 \mathrm{~d}$ \\
370 & 1d to $4 \mathrm{~d}$ \\
670 & $4 \mathrm{~d}$ to $10 \mathrm{~d}$ \\
1100 & $20 \mathrm{~d}$ to $>30 \mathrm{~d}$
\end{tabular}




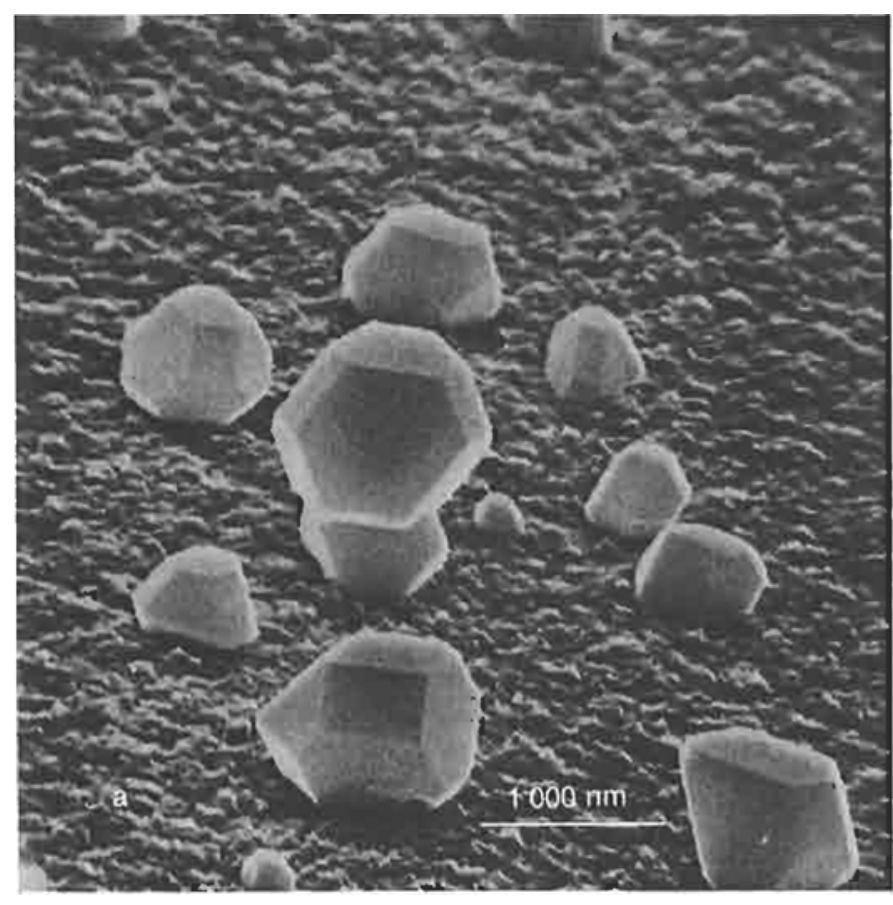

The recovery of lattice defects, recrystallization and the growth of crystals with low specific energy are made at the expense of crystals with high specific energy. This effect is called Ostwald ripening and has been treated theoretically by Wagner (25). By consideration of the changes in specific energy, it can be shown that the relaxation of mechanical stresses yields a gteater driving force than the recovery of defects (22).

Assuming that a gold film is stress-free at the deposition temperature, the positive difference between the thermal expansion coefficient of gold and that of its silicon substrate $\left(\alpha_{\mathrm{Au}}-\alpha_{\mathrm{Si}}\right)$ introduces a compressive stress at elevated temperatures. This can be lowered by partially reducing the volume per area $F$ :

$$
\Delta V=2 d \Delta F\left(\alpha_{A u}-\alpha_{S i}\right) \Delta T
$$

With the experimental data $d=600 \mathrm{~nm}, \Delta T=100$ to $250 \mathrm{~K},\left(\alpha_{\mathrm{Au}}-\alpha_{\mathrm{Si}}\right)=6.7 \times 10^{-6} / \mathrm{K}$ one finds $\Delta V / \Delta F=$ 0.8 to $2 \mathrm{~nm}^{3}$ per $\mathrm{nm}^{2}$, this being much lower than the observed volume of the faceted crystals (20 to $200 \mathrm{~nm}^{3}$ per $\mathrm{nm}^{2}$ ). The crystal growth must then be governed by the Ostwald ripening.

Indeed, using the results of Wagner (25) and equating the diffusion flow of gold at the surface of the thin films with the volume growth of the faceted crystals, it is possible to predict for ageing temperatures of 523 to $633 \mathrm{~K}$ and times of 10 to $200 \mathrm{~h}$, average crystal radii of 500 to $800 \mathrm{~nm}$, which agrees well with experimental observations.

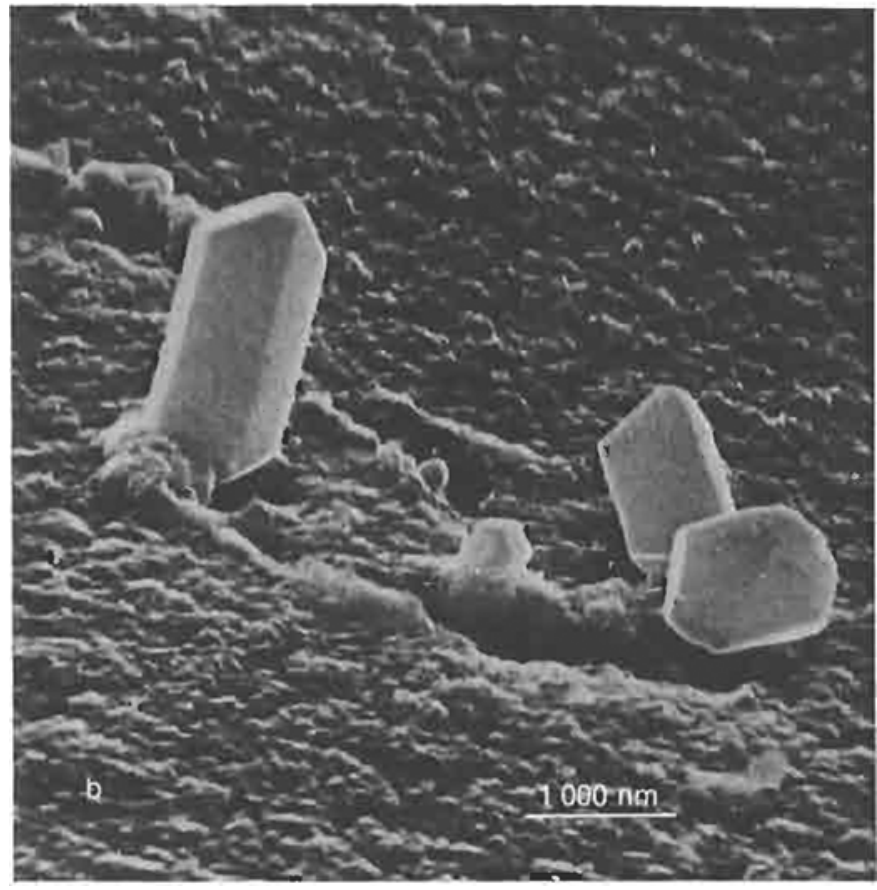

Fig. 12 Examples of crystal ripening on different gold thin film/adhesion layer combinations aged in helium

(a) Type VI metallization of Table I, heat treated at $664 \mathrm{~K}$ for $166 \mathrm{~h}$

(b) Type Vul metallization of Table I, heat treated at $664 \mathrm{~K}$ for $166 \mathrm{~h}$

$$
\times 10600
$$

(c) Type $V$ inetallization of Table I, heat treated at $684 \mathrm{~K}$ for $169 \mathrm{~h}$

$\times 12200$

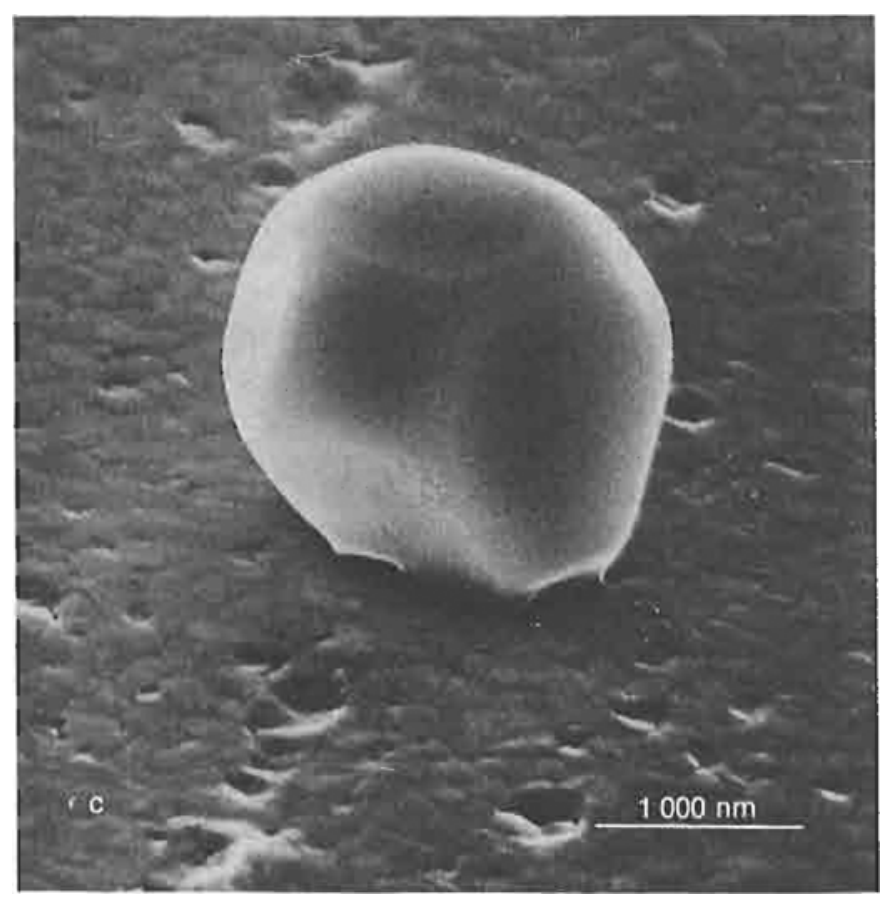




\section{Stability of Thin Gold Films}

Thin metal films are susceptible to ageing. This is due to the high density in them of lattice defects and to stresses arising from the composite nature of the gold/substrate system.

Ageing affects the reliability of components and circuits which incorporate thin films of metals (including gold) and its results can be used to characterize thin film technology (26). To establish reliability, it is necessary to predict property changes for a given batch of devices from ageing experiments on samples from that batch.

Two fundamental problems are attached to obtaining meaningful data from ageing investigations. First, the extrapolation of changes in physical properties observed in accelerated experiments under high loads in order to predict the changes which will occur in long-term use under smaller operating loads is difficult in practice. Secondly, it is not always possible to distinguish between failures which develop gradually and those which occur catastrophically through a variety of causes. Both problems have been solved in only a few relatively simple cases. The operating behaviour of components can be forecast only if the dominant ageing process which governs changes in their technical specifications can be related to point defect reactions (recovery and diffusion) within ranges shorter than the minimum grain size, to chemical reactions and phase formation, for example diffusion of the adhesion layer to the free surface, or to changes in structure with interaction distances longer than the grain size and film thickness. This is an approximate classification of partially overlapping phenomena such as recovery, recrystallization, grain boundary migration and interdiffusion.

Summarizing the evidence collected from Faraday onwards, one might conclude that 'thin film metallizations are not stable' (27). However, thin gold films can be, and are, made very stable, particularly when the technical reliability of professional electronic equipment is required. It can be concluded, from the ageing experiments described above, that the probability of reliable functioning of devices containing thin gold films will be increased if the following conditions are satisfied:

(1) The grain size is uniform with a maximum grain diameter approximately 4 times the film thickness (11)

(2) Interdiffusion via grain boundaries is minimized by stabilization of the adhesion layer (26)

(3) Any mechanical disturbance of the metallization, except microwelding, should be avoided (22)

(4) Thermal cycling due to heat-sink soldering, photo-resist baking and other necessary production steps is reduced to a minimum (10).

\section{References}

1 P.B. Ghate, J.C. Blair and C.R. Fuller, Thin Solid Films, $1977,45,69-84$

2 D. Gupta and P.S. Ho, Thin Solid Films, 1980, 72, 399-418

3 H. Hieber, Int. Inst. Weid. Doc. No. 261/79, 1979

4 M. Faraday, Philos. Trans., 1875, 147, 145-181

5 Z. Marinkovic and V. Simic, Thin Solid Films, 1981, 75, 229-235

6 G.W.B. Ashwell and R. Heckingbottom, J. Electrochem. Soc., 1981, 128, 649-654

7 J.M. Poate, Gold Bull., 1981, 14, 2-10

8 E. Kinsbron, I.A. Blech and Y. Komen, Thin Solid Films, 1977, 46, 139-151

9 H. Hieber, Thin Solid Films, 1976, 37, 335-343

$10 \mathrm{H}$. Hieber, F. Betke and K. Pape, Electrocomponent Sci. Technol., 1977, 4, 89-94

11 R. Ortler, H. Hieber and F. Haessner, to be published in Thin Solid Films

R. Ortler, Diploma work, Tech. Univ. Braunschweig, 1980/81

12 'Recrystallization of Metallic Materials', edited by F. Haessner, Dr Riederer Verlag, Stuttgart, 1978, p.1

13 C.J. Meechan and J.A. Brinkman, Phys. Rev., 1956, 103, 1193-1202
14 G. Moya, Acta Metall., 1975, 23, 289-300

$15 \mathrm{~J}$. Diehl, in 'Moderne Probleme der Metallphysik I', edited by A. Seeger, Springer Verlag, Berlin. Heidelberg, New York, 1968, pp. 227-329

16 T. Ahrens, Study work, Tech. Univ. Berlin, 1979, (in collaboration with H. Hieber)

17 M. v. Heimendahl, 'Einführung in die Elektronenmikroskopie', Vieweg Verlag, Braunschweig, 1970

18 R.D. Doherty, in (12), pp. 23-62

19 F. Haessner and S. Hofmann, in (12), pp. 63-96

20 I. Markov and R. Kaischew, Thin Solid Films, $1976,32,163-167$

21 T.P. Darby and C.M. Wayman, J. Cryst. Growth, 1975, 28, 41-67, and $1975,29,98-108$

22 H. Hieber and K. Pape, Z. Metallkd., 1979, 70, 459-466

23 G.E. Rhead, Sutf, Soi. 1975, 47, 207-221

24 D. Gupta, Thin Solid Films, 1975, 25, 231-244

25 C. Wagner, Z. Elektrochemie, 1961, 65, 581-591

26 W. Goedbloed, H. Hieber and A.G. van Nie, Radio Electron. Eng. $1978,48,13-22$

27 H. Hieber, Phys. Bl., 1979, 35, 455-459 